\title{
Effect of Antidiuretic Hormone and Dibutyryl cAMP upon the Urinary Concentrating Capacity in Neonatal Piglets
}

\author{
R. JOPPICH, ${ }^{251}$ J. SCHRADER, AND D. A. HÄBERLE \\ Universitäts-Kinderklinik $[R . J$.$] . Ph!siologisches Institut of the University of Munich [J . S ., D . A . H$.$] ,$ \\ 8000 Munich 2. Federal Republic of Germany.
}

\begin{abstract}
Summary
In 18-one-day-old anesthetized piglets, the effects of 1-deamino8-D-arginine-vasopressin (DDAVP) with and without administration of dibutyryl adenosine $3^{\prime}: 5^{\prime}$-monophosphate (DBcAMP) upon the urinary concentrating system were studied. Supramaximal doses of $20 \mu \mathrm{g}$ DDAVP per $\mathrm{kg}$ body weight did not affect fractional water and fractional urea excretion, urinary flow rate, and relative urinary osmolarity. The same dose combined with DBCAMP (0.2 $\mathrm{mg} / \mathrm{kg}$ body weight per $\mathrm{min}$ ) changed these parameters significantly. This increase in the responsiveness of the urinary concentrating system to DDAVP by DBcAMP was paralleled by a significant increase in urinary and plasma cyclic adenosine $3^{\prime}: 5^{\prime}$ monophosphate concentration and a tremendous increase in the medullary cyclic adenosine $3^{\prime}: 5^{\prime}$-monophosphate content $(2.5 \times$ $10^{5} \mathrm{pmoles} / \mathrm{g}$ medulla) as compared to the controls $\left(6.4 \times 10^{2}\right.$ pmoles/g medulla) and the animals which received DDAVP without DBCAMP $\left(8.0 \times 10^{2} \mathrm{pmoles} / \mathrm{g}\right.$ medulla $)$. To exclude the possibility that the increased medullary cyclic adenosine $3^{\prime}: 5^{\prime}$ monophosphate production might be caused by degradation of the dibutyryl derivative, in vitro studies with $\left.\right|^{3} \mathrm{H} \mid \mathrm{DBCAMP}$ were performed. Incubation of labeled DBCAMP with a renal medulla homogenate of a 1-day-old piglet for 30,60 , and $90 \mathrm{~min}$ did not decrease the amount of $\left|{ }^{3} \mathrm{H}\right| \mathrm{DBCAMP}$.
\end{abstract}

\section{Speculation}

The reduced accumulation of cyclic adenosine $3^{\prime}: 5^{\prime}$-monophosphate in response to antidiuretic hormone within the renal collecting duct cells seems to be an important reason for the reduced concentrating capacity of the neonatal kidney.

Several in vitro (15, 19,21) and in vivo (11) studies have focused upon the parallelism between the development of the antidiuretic hormone $(\mathrm{ADH})$-sensitive cyclic adenosine $3^{\prime}: 5^{\prime}$-monophosphate (cAMP) system and the development of the concentrating capacity during the neonatal period. It was found that the responsiveness of the medullary adenylate cyclase to $\mathrm{ADH}$ is decreased, but it increases with age (19). Furthermore, it has been suggested that the metabolism of cAMP in the neonatal renal medulla is altered $(6,14)$, so that the accumulation of cAMP in response to ADH is impaired. If such an intracellular "lack" of cAMP is a primary cause of the limitation of neonates to elevate urinary concentration, an increase of the medullary cAMP content by exogenous administration of cAMP should be followed by an increase in urinary concentration. However, administration of cAMP in vivo is difficult because it penetrates through cell membranes very slowly and is rapidly degraded by the phosphodiesterase (20). We therefore infused in the present study dibutyryl adenosine $3^{\prime}: 5^{\prime}-$ monophosphate (DBcAMP) to 1-day-old newborn piglets, in which in an earlier study exogenous administration of ADH had been shown to be ineffective (11). It has been proposed that this analog of cAMP is more rapidly transported across cell membranes and is less quickly hydrolyzed intra- and extracellularly by the phosphodiesterase than the naturally occurring cAMP (18). DBCAMP when injected in vivo in human infants, produced only minimal side effects (23).

\section{MATERIALS AND METHODS}

Experiments were carried out on 19 piglets (strain: Deutsche Landrasse) weighing 1000 to $1800 \mathrm{~g}$. within the first $24 \mathrm{hr}$ after their birth. The anesthesia of the animals was initiated with an IP injection of Inactin $(60$ to $100 \mathrm{mg} / \mathrm{kg}$ body weight b.w.): Byk Gulden. Konstant. West Germany) and sustained during the experiments by the I.V. injection of Nembutal $(10 \mathrm{mg} / \mathrm{kg}$ b.w.; Boehringer Sohn. Ingelheim. West Germany). The piglets were placed on a heated operating table to maintain their temperature at $37^{\circ} \mathrm{C}$. The trachea was cannulated. and a tube was inserted, and then the right external jugular vein was catheterized for infusion of inulin and isotonic glucose solution. The right femoral artery was catheterized for sampling blood and measuring arterial blood pressure, and the ureters were cannulated for sampling urine specimens. After completion of surgery, the piglets received an infusion of isotonic glucose solution at a rate of $30 \mathrm{ml} / \mathrm{hr} / \mathrm{kg}$ b.w. and an infusion of inulin at a rate of $20 \mathrm{mg} / \mathrm{min} / \mathrm{kg} \mathrm{b}$.w. The procedure induced a diuresis. When urine flow reached a steady state. inulin. urea. CAMP. and osmolarity were determined in plasma and urine for control. After this, the glucose infusion was stopped, but the inulin infusion was continued at the same rate. Then the different protocols were used.

In group 1 (six animals) after the control period. DBcAMP (Boehringer Mannheim, Mannheim West Germany) and I-deamino-8-1)-arginin-vasopressin (DDAVP) (Ferring. Malinö, Sweden $),(0.2 \mathrm{mg} / \mathrm{kg} \mathrm{b.w.} / \mathrm{min}$ and $20 \mu \mathrm{g} / \mathrm{kg}$ b.w., respectively) were infused over $1 \mathrm{hr}$. Blood and urine samples were obtained as described above. After $1 \mathrm{hr}$, the DBcAMP infusion was stopped. an additional infusion of DDAVP $(20 \mu \mathrm{g} / \mathrm{kg} \mathrm{b.w.)} \mathrm{was} \mathrm{adminis-}$ tered over $2 \mathrm{hr}$, and blood and urine samples were repeated. In group 2 (five animals), initially only DDAVP $(20 \mu \mathrm{g} / \mathrm{kg} \mathrm{b.w.)} \mathrm{was}$ infused over $2 \mathrm{hr}$, and blood and urine were sampled. Then a combined infusion of DDAVP $(20 \mu \mathrm{g} / \mathrm{kg} \mathrm{b} . w$.$) and DBCAMP (0.2$ $\mathrm{mg} / \mathrm{kg} \mathrm{b.w./min)} \mathrm{over} \mathrm{l} \mathrm{hr}$ was administered. The collection of urine and blood specimens was performed accordingly as in group 1.

After the measurements, both kidneys were immediately removed and frozen in liquid nitrogen. Medullary cAMP content was determined in group 2, in a control group of sham operated animals, and in a group of animals which received only an infusion of DDAVP. The control group (three animals) received a glucose infusion, and the DDAVP group (four animals) received an additional infusion of DDAVP $(20 \mu \mathrm{g} / \mathrm{kg} \mathrm{b.w.})$. After $2 \mathrm{hr}$, the kidneys were removed and frozen in liquid nitrogen. 
To assess whether DBcAMP can be degraded in the renal medulla, a further experimental series was performed. Slices of renal medulla of a 1-day-old piglet were prepared and pooled in ice-cold Tris- $\mathrm{HCl}$ buffer solution ( $\mathrm{pH} 7.4: 10 \mathrm{mM}$ ), immediately homogenized in a Potter $\mathrm{S}$ homogenizer (Braun-Melsungen, Melsingen, West Germany), and then sonified for additional $30 \mathrm{sec}$ with ultrasound (Branson instruments, Inc., Danbury, CT). The assay mixture (final volume, $1 \mathrm{ml}$ ) consisted of $0.12 \mu \mathrm{Ci}\left[{ }^{3} \mathrm{H}\right]-$ DBCAMP (Amersham. Buckinghamshire, England) and $20 \mu \mathrm{M}$ unlabeled DBcAMP (Boehringer Mannheim) in $25 \mathrm{mM} \mathrm{N}-2$ hydroxyethyl-piperazine- $\mathrm{N}^{\prime}$-2-ethanesulfonic acid $(\mathrm{pH} 7.4,50$ $\mathrm{mM}$ ). Reaction was initiated with the addition of the renal medulla homogenate $(124 \mu \mathrm{g} / \mathrm{ml})$. After an incubation time of $30,60,90$ min, reaction was terminated by boiling specimens for $5 \mathrm{~min}$. After centrifugation, an aliquot of the clear supernatant was spotted on Sil-G/UV ${ }_{254}$ thin-layer plates (Machery-Nagel, Düren, West Germany) together with carrier amounts of cAMP and DBcAMP and then developed with $n$-butanol:ethyl acetate:methanol:ammonium hydroxide $(25 \%)(7: 4: 3: 4, v / v)$. The UV lightabsorbing areas of the chromatogram representing cAMP and DBcAMP were scraped off and counted for radioactivity in a Packard liquid scintillation spectrophotometer.

\section{ANALYSES}

Inulin was measured in urine and plasma by the antrone method (5): urea was measured by the Berthelot reaction (Asid Diagnostica, Unterschleissheim-Munich. West Germany). Osmolarities in urine and plasma were determined by freezing point depression, and CAMP was determined after Gilman's method (7) using the test kit of Boehringer Mannheim. Urine was analyzed without further preparation. whereas the plasma samples were prepared as described by Hamet et al. (8). To determine the medullary cAMP content, the frozen kidneys were placed on an aluminum plate and kept at a temperature of $-10^{\circ} \mathrm{C}$. The medulla was separated from the cortex and dissected into slices of 100 to 200 $\mathrm{mg}$. Each slice was weighed, added to $2 \mathrm{ml}$ of ice-cold I $\mathrm{N}$ perchloric acid, and homogenized in a Potter $\mathrm{S}$ homogenizer
(Braun-Melsungen, West Germany). ["H]cAMP (for recovery) was added. The homogenate was centrifuged, and the supernatant was purified by columns of aluminum oxide (Serva, Heidelberg. West Germany) and Dowex-50W-X8, 200 to 400 mesh (Bio-Rad Laboratories, Richmond, CA) as described by Jacobs et al. (10). The measurements were corrected for recovery (about $60 \%$ ).

The assay itself is not sensitive to DBcAMP as has been previously demonstrated (13). In addition, we found that no cAMP could be detected when DBcAMP was added to the assay.

\section{CALCULATIONS}

The results are expressed as the mean \pm standard deviation. Student's $t$ test was used for significant differences between mean values.

\section{RESULTS}

Table 1 shows that glomerular filtration rate as measured by inulin clearance was neither affected by the infusion of DDAVP nor DDAVP and DBcAMP. In both groups, the infusion of DDAVP and DBcAMP was followed by changes of fractional water, $U / P_{\ldots \ldots m}$, fractional urea excretion. (Fig. 1) and of absolute urea clearance and urine flow (Table 1). In group 1 (initially DDAVP and DBcAMP and then DDAVP alone) these effects attenuated when the infusion of DBcAMP was stopped, but the infusion of DDAVP repeated. In group 2 (initially DDAVP alone. then DDAVP and DBCAMP), no effects of DDAVP alone on the above parameters were observed.

The data of the medullary cAMP content is given in Figure 2. In control animals which had received only glucose solution medullary cAMP content was $8.0 \pm 2.6 / 10^{2} \mathrm{pmoles} / \mathrm{g}$ medulla. These values did not differ significantly from the data of the animals which only had received DDAVP. The medullary cAMP content in this group was $6.4 \pm 2.5 \times 10^{2}$ pmoles $/ g$ medulla. However, when DDAVP with DBcAMP was infused, the medullary cAMP content increased tremendously to $2.5 \pm 1.0 \times 10^{\circ}$ pmoles/g medulla. These effects were paralleled by changes of cAMP concentration in urine and blood (Table 1 ).

Table 1. Effect of DDAVP and DDAVP plus DBCAMP on urinary concentration, urinary cAMP excretion, and plasma cAMP

\begin{tabular}{|c|c|c|c|}
\hline Group I & Control & $\begin{array}{l}\text { DBcAMP + } \\
\text { DDAVP }\end{array}$ & DDAVP \\
\hline No. of samples & 16 & 20 & 16 \\
\hline $\mathrm{C}_{\mathrm{t}, 1}{ }^{1}(\mathrm{ml} / \mathrm{min}$ g kidney $\mathrm{wt})$ & $0.23 \pm 0.07^{2}$ & $0.20 \pm 0.08$ & $0.23 \pm 0.07$ \\
\hline $\mathrm{C}_{11}(\mathrm{ml} / \mathrm{min} \mathrm{g}$ kidney $\mathrm{wt})$ & $0.21 \pm 0.07$ & $0.17 \pm 0.07^{3}$ & $0.18 \pm 0.05$ \\
\hline$C_{11} / C_{I 11}$ & $0.93 \pm 0.11$ & $0.85 \pm 0.10^{4}$ & $0.82 \pm 0.11$ \\
\hline $\mathrm{V}(\mu \mathrm{l} / \mathrm{min} \mathrm{g}$ kidney $\mathrm{wt})$ & $10.50 \pm 5.68$ & $3.44 \pm 2.03^{5}$ & $5.13 \pm 2.81^{4}$ \\
\hline $\begin{array}{l}\text { Urinary cAMP excretion (pmoles/min } \\
\text { g kidney wt) }\end{array}$ & $16.89 \pm 5.95$ & $179.65 \pm 66.71^{5}$ & $90.53 \pm 43.77^{5}$ \\
\hline Plasma cAMP (pmoles/ml) & $54.62 \pm 23.54$ & $1040.07 \pm 547.28^{5}$ & $610.44 \pm 310.21^{1}$ \\
\hline Group 2 & Control & DUAVP & $\begin{array}{l}\text { DBcAMP + } \\
\text { DDAVP }\end{array}$ \\
\hline No. of samples & 12 & 16 & 16 \\
\hline$C_{\text {In }}(\mathrm{ml} / \mathrm{min}$ g kidney wt $)$ & $0.22 \pm 0.06$ & $0.20 \pm 0.04$ & $0.19 \pm 0.05$ \\
\hline $\mathrm{C}_{11}(\mathrm{ml} / \mathrm{min} \mathrm{g}$ kidney $\mathrm{wt})$ & $0.16 \pm 0.04$ & $0.14 \pm 0.06$ & $0.10 \pm 0.05^{3}$ \\
\hline$C_{1} / C_{n}$ & $0.73 \pm 0.11$ & $0.71 \pm 0.12$ & $0.53 \pm 0.13^{5}$ \\
\hline $\mathrm{V}(\mu \mathrm{l} / \mathrm{min} \mathrm{g}$ kidney $\mathrm{wt})$ & $6.28 \pm 3.90$ & $6.50 \pm 3.04$ & $3.67 \pm 2.42^{4}$ \\
\hline $\begin{array}{l}\text { Urinary cAMP excretion (pmoles/min } \\
\text { g kidney wt) }\end{array}$ & $15.69 \pm 9.38$ & $12.61 \pm 4.15$ & $143.36 \pm 44.80^{\circ}$ \\
\hline Plasma cAMP (pmoles/ml) & $71.42 \pm 32.55$ & $82.83 \pm 12.85$ & $2055.76 \pm 742.34$ \\
\hline
\end{tabular}

${ }^{\prime} C_{1 \ldots}$ inulin clearance; $C_{11}$, urea clearance; $V$, urinary flow rate per min and $g$ kidney weight.

Mean \pm S.D.

" $P<0.05$

$+P<0.01$

s $P<0.001$. 

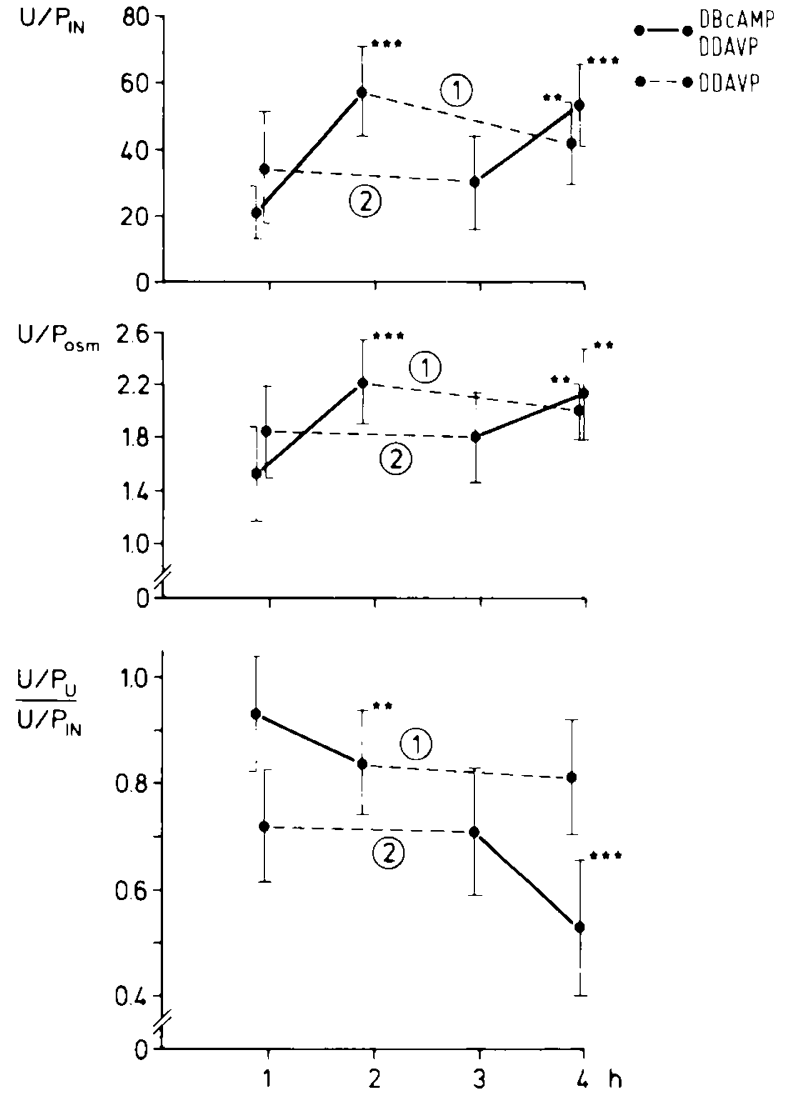

Fig. I. Effect of DDAVP (- --$)$ and DDAVP with DBcAMP $(-)$ on fractional water, $U / P_{\ldots+\cdots,}$ and fractional urea excretion. All values are given as mean \pm S.D. Numbers in circles, groups 1 and $2{ }^{* *}, P$ $<0.01{ }^{* * *}, P<0.001$.

In vitro experiments with $\left[^{3} \mathrm{H}\right] \mathrm{DBcAMP}$ excluded the possibility that the increased medullary CAMP content after the simultaneous application of DDAVP and DBcAMP resulted from degradation of the dibutyryl derivative. The incubation of ["H]DBcAMP with a homogenate of the renal medulla for 30,60 , and $90 \mathrm{~min}$ did not decrease the amount of $\left[{ }^{\prime} \mathrm{H}\right] \mathrm{DB}$ CAMP. recovered in the chromatogram. The corresponding rates were 1739,1613 , and $1772 \mathrm{cpm}$ (results represent the mean of duplicate determinations of each). In addition, neither $\left[{ }^{3} \mathrm{H}\right] \mathrm{cAMP}$ nor any other radioactive metabolites were recovered.

\section{DISC USSION}

With these experiments, we studied the effects of DDAVP and DBcAMP on the renal concentrating system of newborn piglets by measuring their urinary flow rate. fractional water, fractional urea excretion. and $U / P_{\ldots . m .}$. The decrease of urinary flow rate and the increase of fractional water reabsorption and $U / P_{w-m}$ in response to DDAVP and DBCAMP may be attributed to increasing effects of both drugs by changing the level of their endogenous cAMP production.

The main observation of this study is that the infusion of DDAVP does elicit an increase in urine osmolarity only when it is applied together with DBcAMP. This implies the following two conclusions. The restricted concentrating capacity of the renal medulla during the neonatal state results primarily from the reduced responsiveness of the medullary cAMP system to $\mathrm{ADH}$ and not, as it had been proposed in earlier papers, from the structural immaturity of the loop of Henle (2) or the reduced urea excretion (4). Nevertheless, the relatively small increase in urinary osmolarity as compared to the adult state after the application of DDAVP and DBcAMP suggests further that other important components of the renal concentrating system are immature.
Secondly, because the increase in urinary concentration in response to the infusion of both DDAVP and DBcAMP is paralleled by a tremendous increase in medullary cAMP content, we suppose that it is the impaired accumulation of CAMP in the medullary tissue which restricts the concentrating capacity of the neonatal kidney. This view is also supported by findings in vitro. In newborn rats $(19,21)$, the responsiveness of the medullary adenylate cyclase to $\mathrm{ADH}$ was found to be reduced, but the activity of the medullary phosphodiesterase was found to be increased $(6,14)$.

The increase of the medullary cAMP content in response to the infusion of DDAVP and DBcAMP remains unclear. Inasmuch as the infusion of DDAVP alone was ineffective, one may assume that this increase may be attributed to DBcAMP.

It is unlikely that the increase of the medullary cAMP content during the combined infusion of both drugs results from a degradation of the infused DBcAMP. This follows from our in vitro results. When $\left[{ }^{3} \mathrm{H}\right] \mathrm{DBc} A M \mathrm{P}$ was incubated with a homogenate of the newborn renal medulla no [ $\left.{ }^{3} \mathrm{H}\right] \mathrm{cAMP}$ nor other metabolites were detected. This is similar to findings with adipose and bone tissue $(1,9)$, but not to studies on the adult rat renal medulla (3). cell cultures $(12,17)$, and isolated bovine thyroid cells (22). If one assumes that cAMP as measured in the renal medulla represents predominantely intracellular cAMP, it is also unlikely that cAMP, which might have been degraded from DBcAMP in other tissues, may considerably increase cAMP content. This assumption results from the low permeability of the cell membranes to cAMP and the fact that the concentration in the medullary tissue is several magnitudes higher than that in the plasma (24). Therefore, it is more likely that the effect of DDAVP and-DBcAMP on the medullary cAMP content results predominantly from the stimulated synthesis of cAMP by the medullary adenylate cyclase in response to the applied DDAVP and the prevented destruction of this cAMP by DBcAMP inhibiting the activity of the phosphodiesterase, as it had been reported by others $(3,16)$.

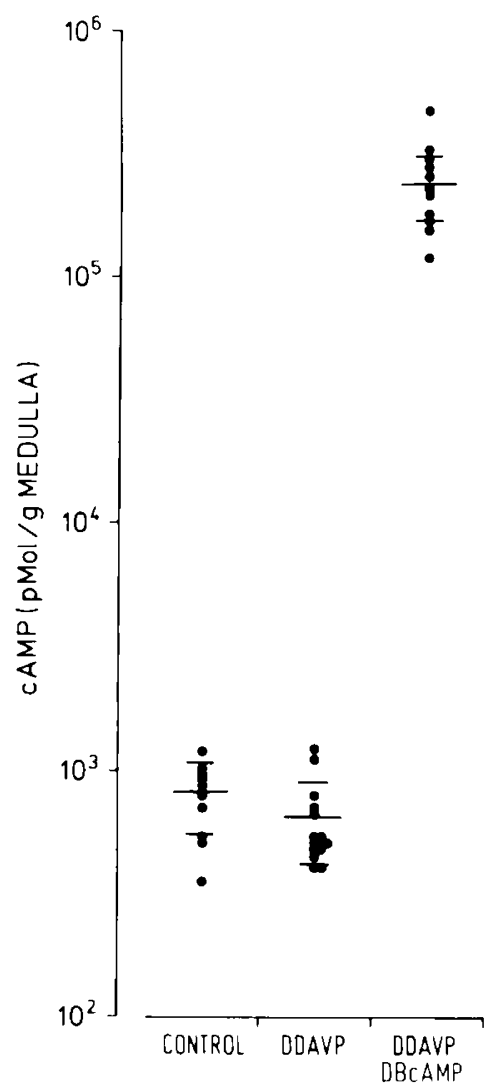

Fig. 2. Medullary CAMP content in controls and in animals which received DDAVP and DDAVP with DBCAMP. Mean \pm S.D. 
Thus, in conclusion, our data support the view that an altered metabolism of cAMP in the renal medullary tissue is a primary factor which restricts the concentrating capacity of the neonatal kidney.

\section{REFERENCES AND NOTES}

I. Blecher, M. RoiAne. J. T., and Flynn, P. D.: Metabolism of dibutyryl cyclic adenosine 3'.5'-monophosphate during its regulation of lipolysis and glucose oxidation in isolated rat epididymal adipocytes. J. Biol. (hem.. 245: 1867 (1970).

2. Boss. J. M. N.. Dlouha. H. Kraus. M.. and Krecek. J.: The structure of the kidney in relation to age and diet in white rats during the weaning period. $J$. Physiol. (Lond.). 168: 196 (1963).

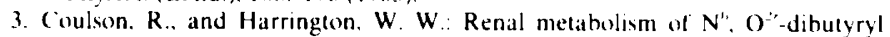
adenosine 3'.5'-monosphosphate. Am. J. Physiol.. 2.37: 175 (1979).

4. Edelmann. ('. M.. Jr.. Barnell. H. L... and Troupkou. V.: Renal concentrating mechanism in newborn infants. Elfects of dietary protein and water content. role of urea, and responsiveness 10 antidiuretic hormone. J. Clin. Invest.. 39: $1062(1960)$.

5. Fuhr. J.. Kaczmarczyk, J.. and Kultgen. (. D.: Eine einfache Methode zur Inulinbestimmung fur die Nieren-( learance-Untersuchungen hei Stoffwechseigesunden und Diabetikern. Klin. Wochenschr.. 3.3: 729 (1955).

6. Ciengler. W. R.. and Forte. 1 .. Neonatal development of rat kidney adenylcyclase and phosphodiesterase. Biochim. Biophys. Acta. 270:367 (1972)

7. Gilman. A (i.: A protein binding assay for adenosine-3'.5'-cyclic monophosphate. Proc. Natl. Acad. Sci. U. S. A.. 67: 305 (1970).

x. Hamet. P.. Kuchel. O.. Fraysse. J.. and (jenest. J.: Plasma adenosine-3'-5'-cyclic monophosphate in human hypertension. (an. Med. Assoc. J.. 11: 323 (1974).

9. Heersche. J. N. M., Fedak. S. A., and Aurbach. ( $;$. D.: The mode of action of dibutyryl adenosine $3^{\prime} .5^{\prime}$-monophosphate on bone tissue in vitro. J. Biol. ('hem., 246: $6770(1971)$

10. Jacobs. K. H., Bohme, E., and Schult. ( $;.$ Determination of cyclic (jMP in biological material. In: J. F. Dumont. B. L. Brown. M. J. Marshall: Eukariotic Cell Function and (jrowth. Regulation by Intracellular (yclic Nucleotides. p. 295 (Plenum Press. New York. 1976).

11. Joppich. R.. Kiemann. U., Mayer. (;.. and Haberle. D.: Effect of antidiuretic hormone upon urinary concentrating ability and medullary cAMP formation in neonatal piglets. Pediatr. Res.. 13:884 (1979).

12. Kaukel. E.. and Hilı. H.: Permeation of dibutyryl cAMP into HeLa cells and its conversion to monohutyryl cAMP. Biochem. Biophys. Res. Commun.. th: $1011(1972)$.
13. Kaukel. E., Mundhenk, K., and Hilz H.: N'-Monobutyryl-adenosine 3',5'monosphosphate as a biologically active derivate of dibutyryladenosine 3'.5'-monophosphate in HeLa S 3 cells. Eur. J. Biochem., 27: 197 (1972).

14. Kleinman, L. I., Wald, A., and Czazkes, J. W.: Maturation of renal enzymes in newborn rats. Pediatr. Res. (Abstract), 11: 553 (1977).

15. L.u. L.-T.. Bailie. M. D.. and Hook. J. B.: Effect of antidiuretic hormone and theophylline on cyclic AMP in renal medulla of newborn and adult rabbits and dogs. (ien. Pharmacol., o: IXI (1975).

16. Miller J. P.. Shuman. D. A.. Scholten. M. B.. Dimmitt. M. K.. Stewart, ('. M. Khwaja. T. A.. Robins. R. K.. and Simon. L. N.: Synthesis and biological activity of some $2^{\prime}$ derivatives of adenosine $3^{\prime} .5^{\prime}$-cyclic phosphate. Biochemistry, 12: $1010(1973)$

17. Nath. J.. and Rebhun. L. I.: Studies on the uptake and metabolism of adenosine 3 '. '-cyclic monophosphate and $N^{\prime \prime}, \mathrm{O}^{\prime}$-dibutyryl 3 '.5'-cyclic adenosine monophosphate in sea urchin eggs. Exp. (ell Res.. $42: 73$ (1973).

18. Posternak. T.. Sutherland, E. W., and Henion. W. F.: Derivatives of eyclic $3^{\prime} .5^{\circ}$ adenosine monophosphate. Biochim. Biophys. Acta. 6.5: $55 \times(1962)$.

19. Rajerison. R.. Butlen. D.. and Jard. S.: Ontogenic development of antidiuretic hormone receptors in rat kidney: comparison of hormonal binding and adenylcylase activity. Mol. Cell. Endocr.. 4: 271 (1976).

20. Robinson. (;. A.. Butcher. R. W.. and Sutherland. F. W.: Some actions of cyclic AMP. In: (;. A. Robinson, R. W. Butcher. E. W. Sutherland: Cyclic AMP. p. 9l (Academic Press Inc.. New York. 1971).

21. Schlondorff. D.. Weber. H.. Trizna. W., and Fine. L. (;.: Vasopressin responsiveness of renal adenylate cyclase in newborn rats and rabbits. Am. J. Physiol. 234: F16 (1978)

22. Szabo. M.. and Burke. ( $;.$ : Uptake and metabolism of 3 '.5'-cyclic adenosine monophosphate and $\mathrm{N}^{\prime \prime} . \mathrm{O}^{\prime}$-dibutyryl $3^{\prime} .5^{\prime}$-cyclic adenosine monophosphate in isolated bovine thyroid cells. Biochim. Biophys. Acta. 264: 289 (1972).

23. Vanderschueren-Lodeweyckx. M.. Van den Berghe. (j.. Proesmans. W.. Corbee. 1... H.ggermont. E.. and Eeckels. R.: Dibutyryl cyclic 3'.5'-adenosine monophosphate in hypopituitarism and Silver-Russel syndrome. Acta Paediatr. Scand. 0.3: 364 (1974).

24. In urine and plasma, a smaller increase of CAMP was observed. This may be related to a small efflux of CAMP from the interior of the collecting duct cells. into urine and bleod.

25. Requests for reprints should he addressed to: Dr. R. Joppich. UniversitatsKinderklinik. L.indwurmstrasse 4. D $-x(x)$ Munich 2. Federal Republic of Giermany.

26. This research was supported by Deutsche Forschungsgemeinschaft. Bonn-Bad Godesberg. Federal Republic of (iermany.

27. Received for publication August 29. 1979.

28. Accepted for publication January 24. 1980. 